\title{
Sleep Disorders in Shift Workers in the Emergency Department and Efficacy of Melatonin
}

\author{
Mücahit Emet' ${ }^{1}$, Mustafa Uzkeser', Sibel Güçlü', Mehmet Ergin², Şahin Aslan' \\ 'Department of Emergency Medicine, Atatürk University School of Medicine, Erzurum, Turkey \\ ${ }^{2}$ Department of Emergency Medicine, Necmettin Erbakan University Meram School of Medicine, Konya, Turkey
}

\begin{abstract}
No statistical data is available on the number of employees working on night shifts in Turkey. Working on shifts is associated with decreased sleep time, decreased daily sleep quality, and decreased alertness during night shifts. Increased incidences of cardiovascular disorders, peptic ulcers, and some types of cancer in shift workers are well known. Exposure to light at nighttime suppresses melatonin production. In non-synchronized circadian rhythm, disturbed melatonin secretion may lead to excessive sleep, hunger for carbohydrates, and weight gain. Melatonin is the hormone that governs sleep. It seems to be the key regulator of the sleep/wake rhythm. Exposure to light at night and disturbance of the circadian rhythm contribute to the health problems of night shift workers by disturbing melatonin production. In this review, the definitions of social jetlag, delayed sleep phase syndrome, and insomnia will be discussed. Sleep disorders in psychiatric diseases will be reviewed. Melatonergic drugs available on the market will be listed, including their contraindications and side effects. The physiopathology of sleep, sleep disorders, depression, and melatonin will be given with an extended discussion. Two recent reviews about the effect of melatonin on sleep patterns will be discussed. Finally, other treatments for sleep disorders will be summarized. In conclusion, in shift workers, sleep problems are a complex subject in which multiple pathophysiological mechanisms play roles. The double-blind randomized controlled studies, systematic reviews, and meta-analyses that have been conducted can provide only weakly positive data about the beneficial effect of melatonin use in shift workers. In the future, multi-centered and multi-participant studies will shed more light on this issue. (Eurasian J Emerg Med 2016; 15: 48-53)
\end{abstract}

Keywords: Melatonin, sleep, review, shift, night work, emergency medicine, agomelatine, melatonergic drugs

\section{Statistics for night shifts and do night shifts lead to health problems?}

In article 69/f.1 of the Republic of Turkey Labor Law no. 4857, the following phrase occurs regarding "night work" and "night work period": "In working life, night is a period that starts latest at 20:00 and lasts until 06:00, with a maximum duration of 11 h." No statistical data are available on the number of employees working on night shifts in Turkey. Studies have revealed that the prevalence of sleep disorders is $5 \%-11 \%$ in day workers and $50 \%-62 \%$ in night workers. The restrictions on social life occur with a frequency of $64 \%$ in night workers (1). In the United States, 29\% of employees are not regular day workers (2). Working on shifts is associated with decreased sleep time, decreased daily sleep quality, and decreased alertness during night shifts (3).

A relationship of insomnia with obesity and metabolic syndrome has been reported (4). The reason for this was increased activity in the amygdala together with decreased activity in the frontal cortex and insular cortex (5).

Kohyama has suggested that the reason why Japan and Korea have the highest suicide rates might originate from the fact that these are countries where the people sleep less or they do not like to sleep (4). When compared with people who sleep for 6-8 $\mathrm{h}$ a day, the suicide rate is 3.5 (HR: 2.0-6.1) times higher in people who sleep for $0-4 \mathrm{~h}$ a day, and sleeping for less than $6 \mathrm{~h}$ is a risk factor for suicide (6). How much sleep is enough for a person? If a person does not feel sleepless when he/she wakes up, sleep time is considered to be sufficient. If he/she feels sleepy, there is a need for longer sleep time (4).

Sleep problems are not merely specific to shift workers, elderly people, and the population who have psychiatric problems. The United States National Health Interview Survey (NHIS) emphasized that $17.4 \%$ of the US population had used products of alternative/ integrative medicine within the last 12 months due to insomnia or problems encountered during falling asleep (7). Lentino et al. reported that more than $25 \%$ of 14,148 soldiers had poor sleep quality and only $33 \%$ stated that they had good-quality sleep (8).

The situation is not different in emergency staff who work at the forefront of the health sector. In a study conducted on female nurses, it has been shown that working in the night shift for a minimum of

Correspondence to: Mücahit Emet e-mail: mucahitemet@gmail.com 
three nights a month for longer than 15 years increased the probability of colon cancer significantly (9). In addition, increased incidences of cardiovascular and metabolic disorders, peptic ulcers, and reproductive dysfunction in shift workers are well known (10-18). A causal link between shift work and cancer has such strong supporting evidence that shift work has been classified as a "probable carcinogen" (19). Besides colorectal cancer, there are many reports about a relation between shift work and endometrial, prostate, and breast cancer (20-22). Exposure to light at nighttime suppresses melatonin production. In non-synchronized circadian rhythm, disturbed melatonin secretion may lead to excessive sleep, hunger for carbohydrates, and weight gain $(11,23)$.

\section{Definitions and Insomnia}

Disorders of biorhythms are known to be mostly associated with changing geographic location (jetlag), aging, and night activity (night shift workers). Jetlag, also known as synchronization disorder, is a status of temporary alterations and irregularities of the 24-h cycle of biologic activity due to sudden changes (1).

In 2006, Wittmann et al. (24) introduced the term of social jetlag in order to describe the undesired physiological and psychological consequences of circadian rhythm that arose from the daily schedule. Then, Randler and Volmer (25) defined this term as an alteration of the sleep pattern during weekdays and holidays and addressed its association with a tendency to physical violence.

Delayed sleep phase syndrome (DSPD) involves a delay in sleep for $2 \mathrm{~h}$ or longer after the routine time for going to bed, leading to difficulty in waking up at the desired time (26). DSPD generally affects adolescents, young adults, and insomnia patients. DSPD has been related to various behavioral and cognitive pathologies (Figure 1) (26).

Insomnia is characterized by the presence of one or more of these symptoms: difficulty in falling asleep, multiple awakenings during the nighttime, getting up very early in the morning, a reduction in total sleep time, somnolence together with an additional need for sleep during the daytime, fatigue, irritability, difficulty in concentrating, and difficulty in carrying out daily tasks (27). The prevalence of insomnia varies between $11 \%$ and $16 \%$ in the community (28-30). Primary insomnia is a difficulty in initiating and maintaining sleep for at least one month (28). Chronic insomnia affects approximately $10 \%$ of the population and is difficult to treat (31).

\section{Sleep Disorders and Psychiatric Diseases}

Sleep disorders are a well-known risk factor in terms of mood disorders, particularly major depression (32). Major depression is a mental disorder characterized by reduction of self-respect, anhedonia (not getting pleasure from activities that were normally liked and loss of interest), fatigue, anxiety, and changes in sleep and body weight, accompanying low mood (28). Depressed patients often complain of difficulty in falling asleep, frequent awakenings in the nighttime, and waking up early in the morning. Of patients with depression, $90 \%$ complain of sleep disorders (33) and 6-29\% complain of hypersomnia (34).

Seasonal affective disorder (SAD) or winter depression is characterized by recurrent seasonal major depressive episodes. It is seen during winter and spring in the absence of seasonal psychosocial stressful situations and the symptoms completely disappear during spring and summer. A seasonal pattern may also be observed in major depression and bipolar depressive disorder. Epidemiological studies have revealed that the incidence of SAD is $15-25 \%$ in the general population. SAD patients manifest atypical depressive symptoms such as a hunger for carbohydrates, hypersomnia, overeating, and weight gain.

In one study, "the description of a sleep disorder by a patient five weeks prior to the recurrence of a depressive episode" was stated to be a major prodromal symptom (35). Abnormalities of rapid eye movement sleep (REMS) are considered to be specific to major depressive disorder (36). Although unipolar and bipolar depression types can be clearly differentiated, no difference was found between the two disorders in terms of nocturnal sleep patterns (36). Conversely, the sleep patterns seen in major depression are not observed in patients with SAD (37). In patients with unipolar and bipolar depressive disorders, melatonin levels were determined to be significantly lower (38).

There are numerous publications that report lower melatonin levels in major depressive disorder; however, some publications have reported the opposite $(39,40)$. Although the average melatonin levels were not found to be different in depressed patients when compared with control cases, the nighttime peak secretion was found to be delayed and levels of 6-sulphatoxymelatonin (a melatonin breakdown product in urine) measured in the morning were higher. This shows that in major depression a phase shift occurs in melatonin production $(41,42)$.

In SAD patients, bright-light therapy is effective in both eliminating the phase anomaly and relieving the depressive symptoms. In a 4-week study, when a bright light of 2500 lux was applied between 06:00 and 08:00, it was demonstrated that the body temperatures, cortisol levels, and moods of the patients returned to those of normal circadian rhythm. When these patients were treated with agomelatine, the relief rate of SAD symptoms was found to be $75.5 \%$ and the rate of remission was $70.3 \%$ (43-47).

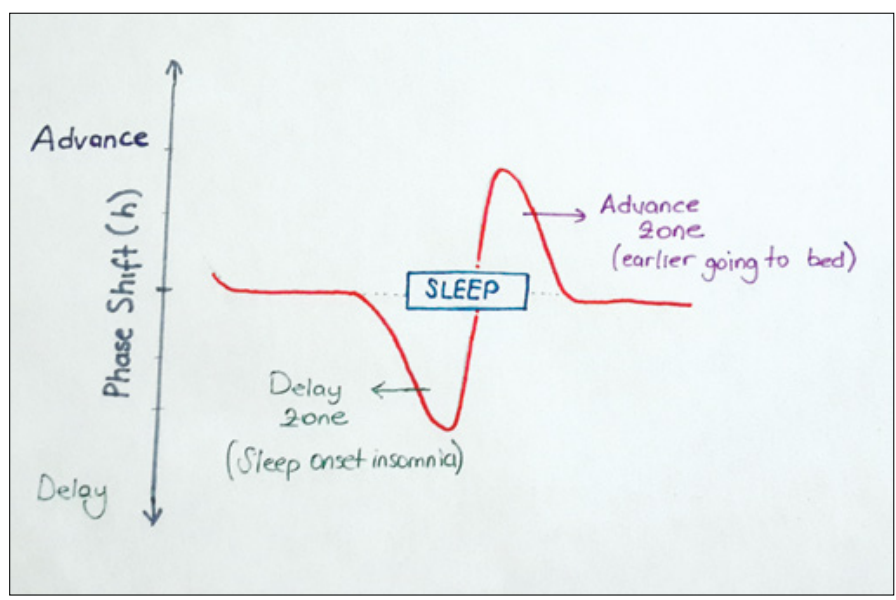

Figure 1. Phase response curve for melatonin: exposure to bright light from just before the time of falling asleep until midnight causes the body clock (and the time of sleepiness) to be delayed. In contrast, bright light in the last couple of hours of the night causes the body clock (and the time of sleepiness) to advance; that is, to shift earlier. Light in the middle of the waking period has no effect on the timing of the body clock. The main symptoms of advanced sleep phase are: 1) falling asleep too early, and 2) waking up too early. Delayed sleep phase is characterized by: 1) falling asleep too late, sometimes after lying in bed awake for many hours, and 2) waking up too late and having trouble getting up on time 


\section{What is Melatonin?}

Melatonin is the hormone that governs sleep. It seems to be the key regulator of the sleep/wake rhythm (36). The circadian signal, which originates from the suprachiasmatic nucleus (SCN), controls being awake throughout the day and sleeping at night. In all animal species, melatonin is secreted to the greatest extent from the pineal gland at night, regardless of whether the status of the living creature is diurnal, nocturnal, or crepuscular (Figure 2) (48). Melatonin is a soporific (sleep-inducing or sleep-initiating) agent (49). It leads to a phase delay when administered in the daytime and when administered in the nighttime a phase-forwarding function occurs (Figure 3) (50). Exposure to light at night and disturbance of the circadian rhythm contribute to the health problems of night shift workers by disturbing melatonin production (Figure 1) (27).

\section{Melatonin Pharmaceuticals on the Market}

For people who have difficulties in falling asleep, short-acting drugs are sufficient. Melatonin reduces sleep latency. Even small doses such as $0.1-0.3 \mathrm{mg} /$ day are sufficient for this purpose (51). All synthetic melatonergic drugs can provide this effect. There are three melatonergic drugs available on the market:

1. Ramelteon (Rozerem $\odot$ ): a non-selective (MT1/MT2) melatonin receptor agonist,

2. Agomelatine (Valdoxan@): a non-selective (MT1/MT2) melatonin receptor agonist and $5-\mathrm{HT}_{2 \mathrm{c}}$ antagonist, and

3. Circadin $\odot$ : prolonged-release melatonin.

In a study conducted by the US NHIS, among respondents to the survey, $5.2 \%$ reported melatonin use and $27.5 \%$ of these gave the reason for using the supplement as insomnia (7).

The drugs that are currently used to treat insomnia are benzodiazepine receptor agonists, antidepressants, antipsychotics, antihistamines and ramelteon, which is a non-selective MT1/MT2 receptor agonist $(28,29)$. Unfortunately, these hypnotic agents cannot induce physiological sleep and in particular their chronic use is related to the development of drug tolerance, rebound insomnia, physical withdrawal symptoms when quitting, sedation, anorexia, anxiety, agitation, tremors, convulsions, and physical and psychological addiction. Therefore, the MT2 receptor may be the new target for inducing physiological sleep (28).

The time of administration of melatonin is important. Although there is not enough evidence for its effect, the administration of melatonin early in the morning and less exposure to light in the morning are recommended for treating an irregular sleep-wake cycle (32). Exogenous melatonin does not affect the blood levels of prolactin, follicle-stimulating hormone, thyroid-stimulating hormone, and estradiol and does not lead to changes in hematological and biochemical parameters (32). If a benzodiazepine is being used for a sleep disorder, melatonin can replace it or, if they are used together, the benzodiazepine dose can be reduced by $25-66 \%$ (32).

Regarding melatonin agonists, liver failure, renal failure, alcohol addiction, and high lipid levels constitute contraindications (52). The side effects of melatonin agonists are nausea, vomiting, headache, elevations in some liver enzyme parameters, rebound insomnia, and, after 6-12 months' use, withdrawal symptoms and addiction (27). There is a risk of hepatotoxicity (53). In experimental animal studies, they are carcinogenic at very high doses (53).

According to a compilation review by Costello et al. (54), no serious side effect was reported for melatonin. The most frequently observed side effects were headache, somnolence, palpitations, and

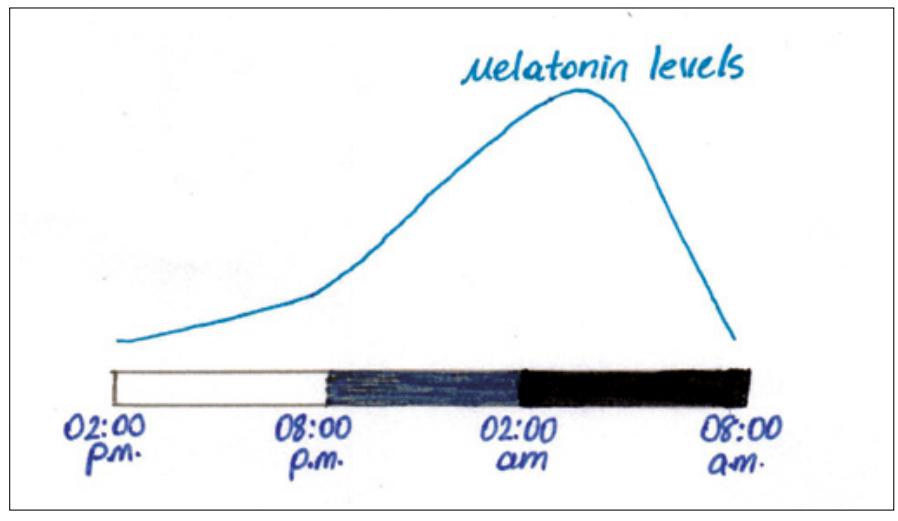

Figure 2. Melatonin levels in a healthy individual during $24 \mathrm{~h}$

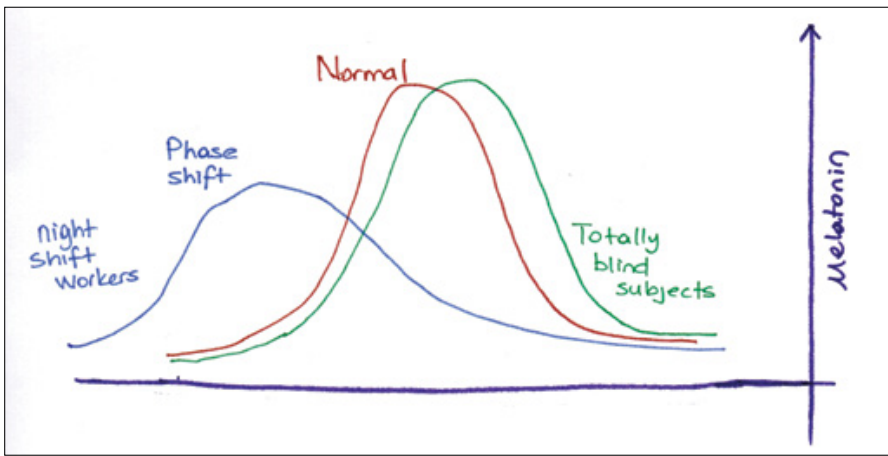

Figure 3. Melatonin levels in normal human, blinded person, and phase shift in a shift worker

abdominal pain. Rarely reported side effects were nasopharyngitis, arthralgia, tachycardia, dizziness, nausea, vomiting, difficulty in swallowing and breathing, hypnotic activity, heaviness of the head, heartburn, belching, swelling of the arms and legs, sweating, hot flushes, exanthema, sleep problems, depression, and sleepwalking (54).

\section{The Physiopathology of Sleep, Sleep Disorders, Depression, and Melatonin}

In mammals, normal sleep is a transition from alertness to stages of non-rapid eye movement sleep (NREMS), in which slow eye movements are present, and REMS (28). Alertness is characterized by low-voltage rapid electroencephalogram (EEG) activity and high muscle tone together with phasic electromyogram activity (28). NREMS is characterized by high-voltage slow EEG activity, reduced muscle tone, characteristic high-voltage slow waveforms (1-4 Hz, $\Delta$ waves), spindles, and K-complexes. REMS or paradoxical sleep is characterized by low-voltage rapid EEG activity together with the absence of muscle tone and a significant $\theta$ rhythm (4-9 Hz) (28). The deep stages of NREMS (stages 3 and 4) are also known as slow wave sleep (SWS). This is suggested to be the most restorative stage of sleep (55). Throughout SWS, numerous physiological processes such as memory consolidation, metabolic arrangement, and blood pressure reduction are maintained (28). In patients with major depression, SWS and REMS latency are reduced and REMS density increases (28). Increased REMS density occurs in eating disorders, narcolepsy, pre-senile dementia, and some other neuropsychiatric disorders $(28,56)$.

The pharmacological activation of MT2 receptors achieved by using selective partial or total agonist drugs improves NREMS without affecting REMS (28). 
In healthy young individuals, four non-REM stages are observed during sleep, which last for 70-90 minutes. Stage 1 shows a transition from a status of mild alertness to stages of deep sleep and constitutes less than $5 \%$ of total sleep throughout the night. Stage 2 is characterized by sleep K-complexes and sleep spindles. Stages 3 and 4 are the deep stages of sleep and slow waves and unsynchronized delta waves are observed. Then, the individual passes into REMS and NREMS follows this in turn (36).

In depressed patients, a reduction in the number of delta waves during the first NREMS period is observed, together with decreased delta activity throughout the night in polysomnography studies (36). The period from the initiation of sleep to the first REMS period is named REMOL. Whereas the stages of NREMS constitute approximately $80 \%$ of total sleep time, REMS constitutes only $20 \%$. The REMS period is prolonged following every successful cycle. Every night, individuals experience five cycles of NREMS and REMS, each lasting for 70-90 minutes (36). The SCN firing rate decreases during the transition from NREMS to REMS (57).

Conventional antidepressants start to improve the sleep patterns of patients 3-4 weeks following initiation of treatment; however, most of their effects are on REMS and their effects on NREMS are less significant (58). Although antidepressants such as tricyclics and selective serotonin reuptake inhibitors suppress REMS, they increase REMOL (59). Most antidepressants increase the amount of MT1 receptor mRNA in hippocampal regions (60).

\section{What do studies tell us about the effect of melatonin on sleep patterns?}

In a placebo-controlled multi-center study conducted on 711 patients of different nationalities in Europe, a $25 \mathrm{mg} /$ day dose of agomelatine was found to be very effective for the improvement of depressive symptoms (61). The presence of serotonergic antagonism is considered to be a reason for the therapeutic effectivity of agomelatine in cases of more complex depression (62). The superiority of agomelatine to other antidepressants is the absence of any significant side effects. In general, sexual side effects, constipation, weight gain, orthostatic hypotension, and memory problems are not encountered and withdrawal symptoms do not occur when quitting $(26,63,64)$.

Studies on the effect of melatonin for improving sleep irregularities in shift workers are generally conducted on a small number of patients and have durations of one week or less (65). In a meta-analysis of 15 randomized placebo-controlled studies on 718 patients reported in the Cochrane Library in 2014, nine studies were conducted with melatonin, two with hypnotics, two with armodafinil, one with modafinil, and one with "caffeine + nap" (66). Taking melatonin (1-10 mg) after a night shift was found to increase daytime sleep duration (mean difference 24 minutes, 95\% Cl: 9.8-38.9; seven studies, 263 participants, low level of evidence) and nighttime sleep duration (mean difference 17 minutes, 95\% Cl: 3.71-30.22; three studies, 234 participants, low level of evidence), when compared with placebo (66). Melatonin did not affect the period of falling asleep in night shift workers, when compared with placebo (mean difference $0.37 \mathrm{~min}, 95 \% \mathrm{Cl}$ : 1.55-2.29; five studies, 74 participants, low level of evidence) (66).

Armodafinil (150 mg), which is an indirect dopamine receptor agonist, when taken prior to a night shift is associated with being less sleepy and improvement in a simple reaction time test (medium level of evidence). Modafinil is associated with being less sleepy on the
Karolinska Sleepiness Scale and increased wakefulness (medium level of evidence). However, in modafinil users (200 mg), headache (34\% modafinil vs. $23 \%$ placebo) and nausea ( $11 \%$ modafinil vs. $23 \%$ placebo) have been determined to be more frequent. In addition, modafinil was shown to be associated with Stevens-Johnson syndrome (66).

Zopiclone $(7.5 \mathrm{mg})$, which is a non-benzodiazepine hypnotic drug, did not lead to an increase in daytime sleep duration when compared with placebo (low level of evidence). Caffeine intake (300 mg) prior to "night shift + nap" was found to be associated with less sleepiness according to the Karolinska Sleepiness Scale (low level of evidence) (66).

In the compilation review by Costello et al. (54) in 2014, 35 randomized clinical studies among 557 articles and a total of 2,356 subjects were included in a study investigating the effect of melatonin on sleep (54). However, in these studies, melatonin dose $(0.3-10 \mathrm{mg})$ and frequency of usage showed great variations among studies (54). In the review, the effects of melatonin in four different kinds of populations were as follows:

1. Shift workers: In an evaluation of the effect of melatonin on falling asleep in eight randomized controlled studies with 300 participants, melatonin was found to be effective in all low-quality studies; however, all high-quality studies reported that there were no satisfactory data for reaching such a conclusion (54). As a result, studies have reported that data that might have enabled any recommendations on melatonin usage in shift workers were not present (54).

2. Jetlag: The efficacy of melatonin usage for jetlag treatment was investigated in eight randomized controlled studies with 972 participants (54). Six out of eight studies found that melatonin usage was effective. In one of the studies, melatonin was found to increase fatigue on the following day $(54,67)$.

3. Insomnia: The efficacy of melatonin was investigated in insomnia patients in four high-quality studies with 845 participants (54). As in jetlag patients, so also in this group, owing to the small size of the patient population not being able to create sufficient statistical power, melatonin usage remained a low-level recommendation (54).

4. Healthy Volunteers: The investigation of 223 healthy volunteers in 15 randomized controlled studies revealed that melatonin usage may be weakly recommended for falling asleep, owing to the small sample sizes (54). Melatonin usage is also weakly recommended for daytime sleeplessness in healthy individuals (54). Sufficient data are not present about melatonin usage for improving hormonal phase shift in healthy individuals.

According to the results of this study, melatonin prevents phase shifts in jetlag and improves insomnia in healthy individuals. However, there are insufficient data on the effect of melatonin in shift workers (54). At physiological doses $(0.1-0.3 \mathrm{mg})$, melatonin is effective for both the initiation and the maintenance of sleep. For its phase shift effect, higher doses $(0.5 \mathrm{mg})$ of melatonin are needed (54). Oral usage of melatonin at doses of $0.3 \mathrm{mg}$ or less increases daytime melatonin levels to nighttime levels (54).

Daytime oral administration of melatonin in healthy individuals may lead to significant drowsiness, fatigue, and poor performance, particularly at its peak 3-4 $\mathrm{h}$ following oral intake (54). If melatonin is used to initiate sleep during the daytime, undesired circadian phase shifts may occur (54). 


\section{What are the Other Treatments for Sleep Disorders?}

The American Academy of Sleep Medicine recommends melatonin, hypnotic medications, and modafinil in shift workers. It has no specific recommendations regarding the clinical usage of caffeine. It suggests that the benefits of modafinil outweigh its harmful effects. However, a Cochrane meta-analysis study has reported that its benefits are fewer, but adverse effects were frequent $(66,68)$; because of its slight benefit and the risk of Stevens-Johnson syndrome, the European Medicines Agency canceled the license of modafinil for shift workers (65).

Another treatment of sleep irregularities is light therapy. This treatment is effective, especially in elderly people; the response is at the moderate level in young individuals. For this purpose, the patient is exposed for 1-2 $\mathrm{h}$ (between 19:00 and 21:00) to bright blue light (2500-10000 lux) (20). If the patient needs to receive light during the daytime, he/she is exposed to 2500-5000 lux for 2 daytime hours for a duration of 4 weeks (Figure 1). Light therapy was found to be effective in numerous disorders such as sleep disorders due to antisocial personality disorder or aging, major depressive disorder, and seasonal depression (32). Dowling et al. (69) found that light therapy was not effective alone for the treatment of sleep disorders in Alzheimer's disease. They reported that when light therapy and melatonin were used together, daytime wakefulness and activity levels increased and the resting-activity rhythm was enhanced (69). Another beneficial factor that is recommended for sleep disorders is physical exercise.

\section{Conclusion}

In shift workers, sleep problems are a complex subject in which multiple pathophysiological mechanisms play roles. The double-blind randomized controlled studies, systematic reviews, and meta-analyses that have been conducted can provide only weakly positive data about the beneficial effect of melatonin use in shift workers. The biggest reason for this is the fact that the effect of melatonin was not studied in a sufficient number of shift workers. In the future, multi-centered and multi-participant studies will shed more light on this issue.

Peer-review: Externally peer-reviewed.

Conflict of Interest: No conflict of interest was declared by the authors.

Financial Disclosure: The authors declared that this study has received no financial support.

\section{References}

1. Kulaksız Y. Çalışma Sürelerinin İş Kazaları Ve Meslek Hastalıkları Üzerine Etkileri. İş Müfettişi Yardımcılığı Etüdü. Erzurum: T.C. Çalışma Ve Sosyal Güvenlik Bakanlığı Iş Teftiş Kurulu Başkanlığı, 2011.

2. Alterman T, Luckhaupt SE, Dahlhamer JM, Ward BW, Calvert GM. Prevalence rates of work organization characteristics among workers in the U.S.: data from the 2010 National Health Interview Survey. Am J Ind Med 2013; 56: 647-59. [CrossRef]

3. Akerstedt T, Ingre M, Broman JE, Kecklund G. Disturbed sleep in shift workers, day workers, and insomniacs. Chronobiol Int 2008; 25: 333-48. [CrossRef]

4. Kohyama J. The possible long-term effects of early-life circadian rhythm disturbance on social behavior. Expert Rev Neurother 2014; 14: 745-55. [CrossRef]
5. Greer SM, Goldstein AN, Walker MP. The impact of sleep deprivation on food desire in the human brain. Nat Commun 2013; 4: 2259. [CrossRef]

6. Gunnell D, Chang SS, Tsai MK, Tsao CK, Wen CP. Sleep and suicide: an analysis of a cohort of 394,000 Taiwanese adults. Soc Psychiatry Psychiatr Epidemiol 2013; 48: 1457-65. [CrossRef]

7. Bliwise DL, Ansari FP. Insomnia associated with valerian and melatonin usage in the 2002 National Health Interview Survey. Sleep 2007; 30 : 881-4.

8. Lentino CV, Purvis DL, Murphy KJ, Deuster PA. Sleep as a component of the performance triad: the importance of sleep in a military population. US Army Med Dep J 2013: 98-108.

9. Schernhammer ES, Laden F, Speizer FE, Willett WC, Hunter DJ, Kawachi I, et al. Night-shift work and risk of colorectal cancer in the nurses' health study. J Natl Cancer Inst 2003; 95: 825-8. [CrossRef]

10. Hardeland R, Madrid JA, Tan DX, Reiter RJ. Melatonin, the circadian multioscillator system and health: the need for detailed analyses of peripheral melatonin signaling. J Pineal Res 2012; 52: 139-66. [CrossRef]

11. De Bacquer D, Van Risseghem M, Clays E, Kittel F, De Backer G, Braeckman L. Rotating shft work and the metabolic syndrome: a prospective study. Int J Epidem 2009; 38: 848-54. [CrossRef]

12. Brown DL, Feskanich D, Sanchez BN, Rexrode KM, Schernhammer ES, Lisabeth LD. Rotating night shift work and ischemic stroke. Am J Epidemiol 2009; 169: 1370-7. [CrossRef]

13. Fujino $\mathrm{Y}$, Iso $\mathrm{H}$, Tamakoshi A, Inaba $\mathrm{Y}$, Koizumi A, Kubo T, et al. A prospective cohort study of shift work and risk of ischemic heart disease in Japanese male workers. Am J Epidemiol 2006; 164: 128-35. [CrossRef]

14. Lieu SJ, Curhan GC, Schernhammer ES, Forman JP. Rotating night shift work and disperate hypertension risk in African-Americans. J Hypertens 2012; 30: 61-6. [CrossRef]

15. Lund J, Arendt J, Hampton SM, English J, Morgan LM. Postprandial hormone and metabolic responses among shift workers in Antarctica. J Endocrinol 2001; 171: 557-64. [CrossRef]

16. Pan A, Schernhammer ES, Sun $Q$, Hu FB. Rotating night shift work and risk of type 2 diabetes: two perspective cohort studies in women. PLoS Med 2011; 8: e1001141.

17. McDonald AD, McDonald JC, Armstrong B, Cherry NM, Cote R, Lavole J, et al. Fetal death and work in pregnancy. $\mathrm{Br}$ J Ind Med 1988; 45: 148-57. [CrossRef]

18. Marino JL, Holt VL, Chen C, Davis S. Shif work, hCLOCK T3111C polymorphism, and endometriosis risk. Epidemiology 2008; 19: 477-84. [CrossRef]

19. Straif K, Baan R, Grosse Y, Secretan B, El Ghissassi F, Bouvard V, et al. Carcinogenicity of shift work, painting, and fire-fighting. Lancet Oncol 2007; 8: 1065-6. [CrossRef]

20. Viswanathan AN, Hankinson SE, Schernhammer ES. Night shift work and the risk of endometrial cancer. Cancer Res 2007; 67: 10618-22. [CrossRef]

21. Kubo T, Ozasa K, Mikami K, Wakai K, Fujino Y, Watanabe $Y$, et al. Prospective cohort study of the risk of prostate cancer among rotating-shift workers: finding from Japan collaborative cohort study. Am J Epidemiol 2006; 164: 549-55. [CrossRef]

22. Hansen J. Increased breast cancer risk among women who work predominantly at night. Epidemiology 2001; 12: 74-7. [CrossRef]

23. Rosenthal NE, Genhart M, Jacobsen FM, Skwerer RG, Wehr TA. Disturbances of appetite and weight regulation in seasonal affective disorder. Ann NY Acad Sci 1987; 499: 216-30. [CrossRef]

24. Wittmann M, Dinich J, Merrow M, Roenneberg T. Social jetlag: misalignment of biological and social time. Chronobiol Int 2006; 23: 497-509. [CrossRef]

25. Randler C, Vollmer C. Aggression in young adults--a matter of short sleep and social jetlag? Psychol Rep 2013; 113: 754-65.

26. Pandi-Perumal SR, Trakht I, Srinivasan V, Spence DW, Maestroni GJ, Zisapel $\mathrm{N}$, et al. Physiological effects of melatonin: role of melatonin receptors and signal transduction pathways. Prog Neurobiol 2008; 85: 335-53. [CrossRef] 
27. Hardeland R. Melatonin in aging and disease -multiple consequences of reduced secretion, options and limits of treatment. Aging Dis 2012; 3: 194-225.

28. Comai S, Gobbi G. Unveiling the role of melatonin MT2 receptors in sleep, anxiety and other neuropsychiatric diseases: a novel target in psychopharmacology. J Psychiatry Neurosci 2014; 39: 6-21. [CrossRef]

29. Gershell L. Insomnia market. Nat Rev Drug Discov 2006; 5: 15-6. [CrossRef]

30. Morin CM, LeBlanc M, Daley M, Gregoire JP, Merette C. Epidemiology of insomnia: prevalence, self-help treatments, consultations, and determinants of help-seeking behaviors. Sleep Med 2006; 7: 123-30. [CrossRef]

31. National Institutes of H. National Institutes of Health State of the Science Conference statement on Manifestations and Management of Chronic Insomnia in Adults, June 13-15, 2005. Sleep 2005; 28: 1049-57.

32. Campos Costa I, Nogueira Carvalho H, Fernandes L. Aging, circadian rhythms and depressive disorders: a review. Am J Neurodegener Dis 2013; 2: 228-46.

33. Mendelson WB, Sack DA, James SP, Martin JV, Wagner R, Garnett $D$, et al. Frequency analysis of the sleep EEG in depression. Psychiatry Res 1987; 21: 89-94. [CrossRef]

34. Germain A, Kupfer DJ. Circadian rhythm disturbances in depression. Hum Psychopharmacol 2008; 23: 571-85. [CrossRef]

35. Perlis ML, Giles DE, Buysse DJ, Tu X, Kupfer DJ. Self-reported sleep disturbance as a prodromal symptom in recurrent depression. J Affect Disord 1997; 42: 209-12. [CrossRef]

36. Srinivasan V, Pandi-Perumal SR, Trakht I, Spence DW, Hardeland R, Poeggeler B, et al. Pathophysiology of depression: role of sleep and the melatonergic system. Psychiatry Res 2009; 165: 201-14. [CrossRef]

37. Anderson JL, Rosen LN, Mendelson WB, Jacobsen FM, Skwerer RG, Joseph-Vanderpool JR, et al. Sleep in fall/winter seasonal affective disorder: effects of light and changing seasons. J Psychosom Res 1994; 38: 323-37. [CrossRef]

38. Beck-Friis J, Kjellman BF, Aperia B, Undén F, von Rosen D, Ljunggren JG, et al. Serum melatonin in relation to clinical variables in patients with major depressive disorder and a hypothesis of a low melatonin syndrome. Acta Psychiatr Scand 1985; 71: 319-30. [CrossRef]

39. Rao AV, Devi SP, Srinivasan V. Urinary melatonin in depression. Indian J Psychiatry 1983; 25: 167-72.

40. Rubin RT, Heist EK, McGeoy SS, Hanada K, Lesser IM. Neuroendocrine aspects of primary endogenous depression. XI. Serum melatonin measures in patients and matched control subjects. Arch Gen Psychiatry 1992; 49: 558-67. [CrossRef]

41. Etain B, Milhiet V, Bellivier F, Leboyer M. Genetics of circadian rhythms and mood spectrum disorders. Eur Neuropsychopharmacol 2011; 21(Suppl 4): S676-82.

42. Castaneda TR, de Prado BM, Prieto D, Mora F. Circadian rhythms of dopamine, glutamate and GABA in the striatum and nucleus accumbens of the awake rat: modulation by light. J Pineal Res 2004; 36: 177-85. [CrossRef]

43. Heaton P, Davis RE, Happe FG. Research note: exceptional absolute pitch perception for spoken words in an able adult with autism. Neuropsychologia 2008; 46: 2095-8. [CrossRef]

44. Pjrek E, Winkler D, Konstantinidis A, Willeit M, Praschak-Rieder N, Kasper S. Agomelatine in the treatment of seasonal affective disorder. Psychopharmacology (Berl) 2007; 190: 575-9. [CrossRef]

45. Sohn CH, Lam RW. Update on the biology of seasonal affective disorder. CNS Spectr 2005; 10: 635-46.

46. Axelsson J, Karadottir R, Karlsson MM. Differences in prevalence of seasonal affective disorder that are not explained by either genetic or latitude differences. Int J Circumpolar Health 2002; 61: 17-20. [CrossRef]

47. Rosenthal NE, Sack DA, Gillin JC, Lewy AJ, Goodwin FK, Davenport Y, et al. Seasonal affective disorder. A description of the syndrome and preliminary findings with light therapy. Arch Gen Psychiatry 1984; 41: 72-80. [CrossRef]
48. Claustrat B, Brun J, Chazot G. The basic physiology and pathophysiology of melatonin. Sleep Med Rev 2005; 9: 11-24. [CrossRef]

49. Genell H. Melatonin and the pineal gland. J Neurosci Nurs 2002; 34: 74-8. [CrossRef]

50. Uz T, Arslan AD, Kurtuncu M, Imbesi M, Akhisaroglu M, Dwivedi $Y$, et al. The regional and cellular expression profile of the melatonin receptor MT1 in the central dopaminergic system. Brain Res Mol Brain Res 2005; 136: 45-53. [CrossRef]

51. Pandi-Perumal SR, Srinivasan V, Poeggeler B, Hardeland R, Cardinali DP Drug Insight: the use of melatonergic agonists for the treatment of insomnia-focus on ramelteon. Nat Clin Pract Neurol 2007; 3: 221-8. [CrossRef]

52. Hardeland R, Poeggeler B, Srinivasan V, Trakht I, Pandi-Perumal SR, Cardinali DP. Melatonergic drugs in clinical practice. Arzneimittelforschung 2008; 58: 1-10.

53. Agomelatine: new drug. Adverse effects and no proven efficacy. Prescrire Int 2009; 18: 241-5.

54. Costello RB, Lentino CV, Boyd CC, O'Connell ML, Crawford CC, Sprengel ML, et al. The effectiveness of melatonin for promoting healthy sleep: a rapid evidence assessment of the literature. Nutr J 2014; 13: 106. [CrossRef]

55. Walker MP, Stickgold R. Sleep-dependent learning and memory consolidation. Neuron 2004; 44: 121-33. [CrossRef]

56. Thase ME. Depression, sleep, and antidepressants. J Clin Psychiatry 1998 59(Suppl 4): 55-65.

57. Deboer T, Vansteensel MJ, Detari L, Meijer JH. Sleep states alter activity of suprachiasmatic nucleus neurons. Nat Neurosci 2003; 6: 1086-90. [CrossRef]

58. Lam RW. Sleep disturbances and depression: a challenge for antidepressants. Int Clin Psychopharmacol 2006; 21 (Suppl 1): S25-9.

59. Armitage R, Hoffmann R, Fitch T, Trivedi M, Rush AJ. Temporal characteristics of delta activity during NREM sleep in depressed outpatients and healthy adults: group and sex effects. Sleep 2000; 23: 607-17.

60. Imbesi M, Uz T, Yildiz S, Arslan AD, Manev H. Drug- and region-specific effects of protracted antidepressant and cocaine treatment on the content of melatonin $\mathrm{MT}(1)$ and $\mathrm{MT}(2)$ receptor mRNA in the mouse brain. Int $J$ Neuroprot Neuroregener 2006; 2: 185-9.

61. Loo H, Hale A, D'Haenen $\mathrm{H}$. Determination of the dose of agomelatine, a melatoninergic agonist and selective $5-\mathrm{HT}(2 \mathrm{C})$ antagonist, in the treatment of major depressive disorder: a placebo-controlled dose range study. Int Clin Psychopharmacol 2002; 17: 239-47. [CrossRef]

62. Rouillon F. Efficacy and tolerance profile of agomelatine and practical use in depressed patients. Int Clin Psychopharmacol 2006; 21(Suppl 1): S31-5.

63. Krauchi K, Cajochen C, Wirz-Justice A. A relationship between heat loss and sleepiness: effects of postural change and melatonin administration. J Appl Physiol (1985) 1997; 83: 134-9.

64. van den Heuvel CJ, Kennaway DJ, Dawson D. Thermoregulatory and soporific effects of very low dose melatonin injection. Am J Physiol 1999; 276: E249-54.

65. Liira J, Verbeek J, Ruotsalainen J. Pharmacological interventions for sleepiness and sleep disturbances caused by shift work. JAMA 2015; 313 : 961-2. [CrossRef]

66. Liira J, Verbeek JH, Costa G, Driscoll TR, Sallinen M, Isotalo LK, et al. Pharmacological interventions for sleepiness and sleep disturbances caused by shift work. Cochrane Database Syst Rev 2014; 8: CD009776.

67. Claustrat B, Brun J, David M, Sassolas G, Chazot G. Melatonin and jet lag: confirmatory result using a simplified protocol. Biol Psychiatry 1992; 32: 705-11. [CrossRef]

68. Morgenthaler TI, Lee-Chiong T, Alessi C, Friedman L, Aurora RN, Boehlecke $\mathrm{B}$, et al. Practice parameters for the clinical evaluation and treatment of circadian rhythm sleep disorders. An American Academy of Sleep Medicine report. Sleep 2007; 30: 1445-59.

69. Dowling GA, Burr RL, Van Someren EJ, Hubbard EM, Luxenberg JS, Mastick J, et al. Melatonin and bright-light treatment for rest-activity disruption in institutionalized patients with Alzheimer's disease. J Am Geriatr Soc 2008; 56: 239-46. [CrossRef] 